\title{
Construction and Accuracy Analysis of a BDS/GPS-Integrated Positioning Algorithm for Forests
}

\author{
Fei Yan, Xueqi Hu, Lidan Xu, Yongrui Wu
}

\begin{abstract}
The objective of this study was to construct a BeiDou navigation satellite system (BDS)/ global positioning system (GPS)-integrated positioning algorithm that meets the accuracy requirement of forest surveys and to analyze its accuracy to provide theoretical and technical support for accurate positioning and navigation in forests. The Quercus variabilis broad-leaved forest in Jiufeng National Forest Park and the Sabina Coniferous forest in Dongsheng Bajia forest farm were selected as the study area. A Sanding T-23 multi-frequency three-constellation receiver and a u-blox NEO-M8T multi-constellation receiving module were used for continuous observation under the forest canopy. Compared with T-23, the u-blox NEO-M8T is much lighter and more flexible in the forest. The BDS/GPS-integrated positioning algorithm for forests was constructed by temporally and spatially unifying the satellite systems and using a reasonable observed value weighting method. Additionally, the algorithm is also written into the RTKLIB software to calculate the three-dimensional (3D) coordinates of the forest observation point in the World Geodetic System 1984 (WGS-84) coordinate system. Finally, the results were compared with the positioning results obtained using GPS alone. The experimental results indicated that, compared with GPS positioning, there were 13-27 visible satellites available for the BDS/GPS-integrated positioning algorithm for forests, far more than the satellites available for the GPS positioning algorithm alone. The Position Dilution of Precision (PDOP) values for the BDS/GPS-integrated positioning ranged from 0.5 to 1.9, lower than those for GPS positioning. The signal noise ratio (SNR) of the BDS/GPS-integrated satellite signals and GPS satellite signals were both in the range of 10-50 dB-Hz. However, because there were more visible satellites for the BDS/GPS-integrated positioning, the signals from the BDS/GPS-integrated satellites were stronger and had a more stable SNR than those from the GPS satellites alone. The results obtained using the BDS/GPS-integrated positioning algorithm for forests had significantly higher theoretical and actual accuracies in the $X, Y$ and $Z$ directions than those obtained using the GPS positioning algorithm. This suggests that the BDS/GPS-integrated positioning algorithm can obtain more accurate positioning results for complex forest environments.
\end{abstract}

Keywords: GNSS positioning, forest, accuracy assessment

\section{Introduction}

Forestry, as a principal part of ecological civilization construction, plays important ecological, economic, social and cultural roles. To better realize the functions of forestry, maintain healthy development of forests and informatize forest management, precision is of particular importance. Global navigation satellite systems (GNSS) play a tremendous role in fine forest monitoring and management. GNSS can provide realtime, accurate positioning information, occurrence area information and navigation services for core forestry operations, such as forest resource surveys, forest fire prevention and emergency planning, and plant disease and insect pest monitoring, prevention and control. As a result, GNSS are a central topic in global forest survey research (Bettinger et al. 2019, Becker et al. 2017, Brach et al. 2014, Liu et al. 2017). 
However, to date, most research on the application of satellite navigation in forestry has relied on the U.S. Navigation System with Timing and Ranging/Global Positioning System (GPS). GPS technology is relatively mature with an extensive user base and has established an industrial leader role globally (Yang et al. 2016). Wing et al. (2006) investigated the accuracy and reliability of the GPS in a variety of forest conditions in the forest region of Oregon, a western state of the U.S. Sawaguchi et al. (2005) studied the relations between cedar trees, needle pines and broad-leaved forests and the signal-to-noise ratio (SNR) of GPS-receiving satellites. Lai of Sichuan Agricultural University (2005) studied the factors affecting the accuracy of the GPS, concluding that the accuracy of the GPS is relatively closely related to the forest stand canopy density, the dominant forest stand tree species, the observation period and the date. Feng et al. (2004) and Tan et al. (2008), of Beijing Forestry University, extensively investigated positioning results obtained using differential GPS technology in various forest canopy and mountainous terrain conditions, summarizing the effects of land type and terrain on the accuracy of the GPS. Zhang et al. (2014) studied the effects of site condition and positioning mode on the accuracy of the GPS. In 2015, Zhang et al. (2015) conducted an experiment on the use of a satellite-ground-combined positioning approach for high-canopy-density forest stands. Kaartinen et al. (2015) tested the accuracy of various instruments utilizing global satellite navigation systems (GNSS) in motion under forest canopies of varying densities. Overall, because of the unique satellite constellation network of the single GPS and the complexity of forestlands, research on the application of satellite positioning in forest regions has met with problems, such as poor satellite signal, loss of lock on the signal and strong multipath effects in forest environments, resulting in relatively low positioning accuracy or an inability to conduct satellite positioning in forest regions (Feng et al. 2017, Zhang et al. 2015, Li et al. 2014, Xu et al. 2013). Consequently, the positioning accuracy requirement for some forest operations cannot be met.

In addition to GPS, there are Galileo, GLONASS, and Beidou navigation systems, QZSS and IRNSS satellite signal enhancement systems. Improving positioning accuracy through compatibility and interoperability between systems is a current research hot spot. However, more than two system choices could greatly increase the complexity of data solution, i.e. the system options are very important (Zrinjski et al. 2019, Montenbruck et al. 2017, Solarić et al. 2018). In the Asia-Pacific region, with the completion of Beidou, the combination of BDS and GPS is a suitable choice (Zhu et al. 2018). The BeiDou navigation satellite system (BDS) was independently developed by China. It is capable of providing global, continuous, all-weather, high-accuracy, autonomous navigation and positioning services. The BDS consist of 46 satellites operating in three types of satellite orbits, differing in altitude, i.e., medium Earth orbits, geostationary orbits (GEO) and inclined geosynchronous orbits (IGSO) (Liu 2011, 2013, Li et al. 2005). The BDS network was completed in June 23, 2020. Because of the unique high-orbit (GEO and IGSO) satellites of the BDS and the resultant local enhancement for the Asia-Pacific region, there has been a significant increase in the number of satellites and in the quality of satellite signals that can be received within the entire Asia-Pacific region. Even in inclement environments, where tall buildings, trees and canyons cause obstructions, more high-elevationangle visible satellites in the BDS can be received compared to those received by the GPS (Yan et al. 2019, Liu $2003,2015)$. The gaps left by a relatively small number of satellites have been eliminated and multipath effects have been weakened. As a result, the accuracy and precision of positioning under the forest canopy have improved. The BDS provides an important technical means for in-depth research on satellite positioning and navigation for forestry.

In view of the above, a BDS/GPS-integrated positioning algorithm that meets the accuracy requirement of forest resource surveys is constructed using the BDS/GPS-integrated single-point positioning algorithm for forests as the main technical method, the Jiufeng National Forest Park and Dongsheng Bajia forest farm in the Haidian District of Beijing, China as the study area, and a T-23 multi-frequency three-constellation receiver and a u-blox NEO-M8T multi-constellation receiving module as data acquisition equipment. Additionally, the integrated positioning algorithm is also written into the RTKLIB software to calculate the three-dimensional (3D) coordinates of the forest observation point in the World Geodetic System 1984 (WGS-84) coordinate system. Moreover, the results are compared with the positioning results obtained using GPS alone to investigate the effects of high-canopy density forest environments on the number of visible satellites (NVS), the position dilution of precision (PDOP) value and the SNR. Furthermore, the accuracy of the results is also evaluated to verify the advantages of multi-system positioning algorithms in complex forest environment conditions. The results obtained from this study provide a theoretical basis and technical support for research on the application of the BDS in forestry and contribute to the industrialization of the BDS in the forestry field. 


\section{Research Materials}

\subsection{General Information on the Study Area}

The selected broad-leaved forest experimental area (Table 1) is located in the Jiufeng National Forest Park in the Haidian District of Beijing, China. There are rolling mountain ranges and a complex terrain in the park, where the highest peak has an elevation of $1153 \mathrm{~m}$ and the main peak is $465 \mathrm{~m}$. Broad-leaved deciduous forests are the primary vegetation type. Below the lowmountain level $(800 \mathrm{~m})$, there are large areas of manmade forests (Platycladus orientalis, Chinese pine, Quercus variabilis, Robinia pseudoacacia, etc.) dotted with Prunus armeniaca and Vitex negundo shrubs. In the mid-mountain range (800-1100 m), oak-pine forests are the native vegetation and Chinese pine and larch are the primary tree species; the forest coverage is up to $96.4 \%$. Situated on the east side of the park $\left(40^{\circ} 03^{\prime} 49^{\prime \prime} \mathrm{N}\right.$, $\left.116^{\circ} 05^{\prime} 51^{\prime \prime} \mathrm{E}\right)$, the selected study area has an elevation of approximately $130 \mathrm{~m}$, a slope gradient of approximately $22^{\circ}$, and a southeastern slope aspect, as shown in Fig. 1 (left). Data were collected in mid- and late June 2018. Before the experiment began, it had rained multiple times in the forest region. As a result, the soil was soft, which helped to set up the equipment. Quercus variabilis, mostly over 30 years old, is the primary tree species in the study area. Other stand parameters are detailed in Table 1.

The Coniferous forest experimental area (Table 1) is located in the Dongsheng Bajia forest farm, also in the Haidian District of Beijing, China, covering an area of 101.45 ha. There are abundant vegetation species in the experimental area. The coniferous forest is mainly composed of Sabina, Pinus tabulaeformis and Chinese fir, and the broad-leaved forest is dominated by poplar and willow. Situated on the north side of the park $\left(40^{\circ} 01^{\prime} 19^{\prime \prime} \mathrm{N}, 116^{\circ} 20^{\prime} 30^{\prime \prime} \mathrm{E}\right)$, there are no high-rise buildings around the selected study area, and satellite signals can be effectively prevented from being blocked, as shown in Fig. 1 (right). Data were collected in mid-
Table 1 Mean stand characteristics of the study area

\begin{tabular}{|l|c|c|c|c|}
\hline Vegetation type & $\begin{array}{c}\text { Canopy } \\
\text { density }\end{array}$ & $\begin{array}{c}\text { Stand density } \\
\text { tree/ha }\end{array}$ & $\begin{array}{c}\text { Mean DBH } \\
\text { cm }\end{array}$ & $\begin{array}{c}\text { Mean tree } \\
\text { height, } \mathrm{m}\end{array}$ \\
\hline Broad-leaved forest & 0.82 & 564 & 93.0 & 15.2 \\
\hline Coniferous forest & 0.61 & 826 & 21.3 & 5.6 \\
\hline
\end{tabular}

and late April 2019. Sabina chinensis is the primary tree species in this study area and the stand parameters are also detailed in Table 1.

\subsection{Experimental Equipment and Calculation Software}

The equipment used in the study included a Sanding T-23 multi-frequency three-constellation receiver (Fig. 2a), a u-blox NEO-M8T multi-constellation receiving module (Fig. 2b), a tripod, a DBH girthing tape, and a wooden post. The software used in the study included GAMIT (Version 10.61) and RTKLIB (Version 2.4.3). GAMIT was used in the high-accuracy calculation of the 3D coordinates of the forest observation point in the WGS-84 coordinate system to obtain their true values with positioning accuracy in the centimeter range. RTKLIB was used in the programming of the BDS/ GPS-integrated algorithm, the real-time single-point positioning and the accuracy analysis. Both software packages support multiple GNSS standards and construction of precise positioning algorithms, can achieve real-time GNSS positioning and post-processing calculations, and are commonly used to study GNSS-integrated algorithms (Paziewski et al. 2017).

\section{Methods}

\subsection{Observation Point Positioning Data Collection}

An observation point at the center of the forest stand was set up to sufficiently represent its high-canopy
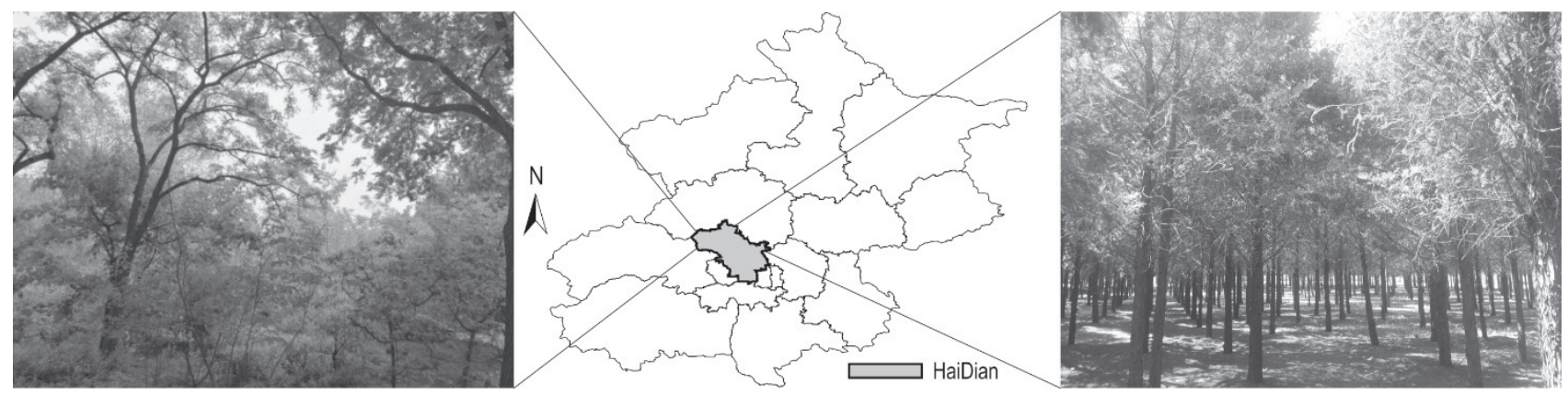

Fig. 1 The study area of broad-leaved forest and Coniferous forest 


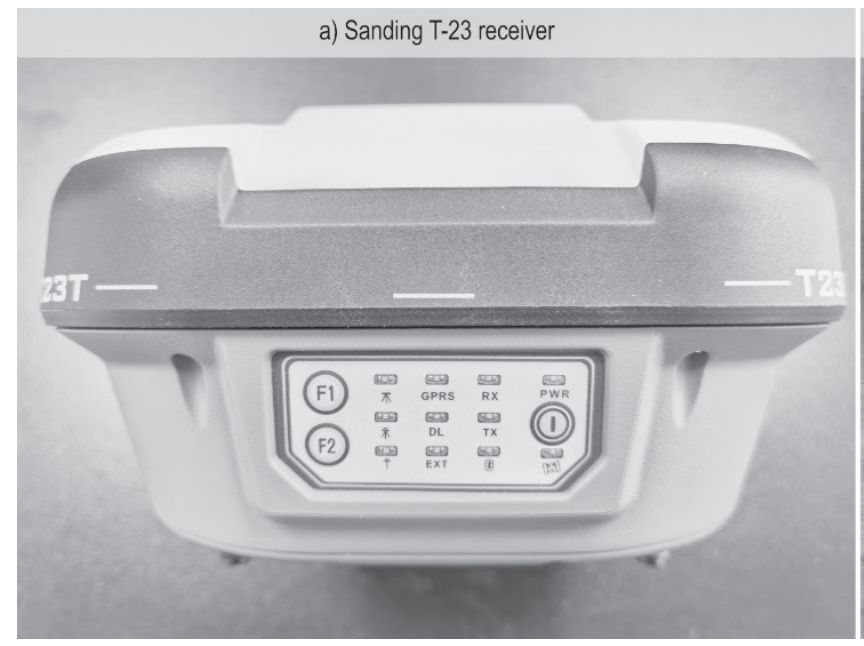

Fig. 2 Experimental instrument and solving software

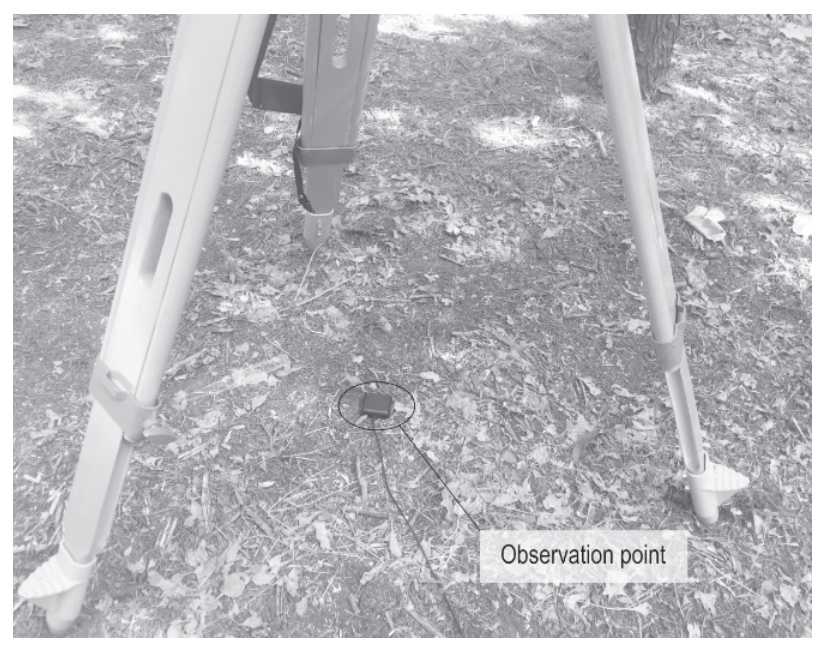

Fig. 3 Observation point setting

density. A wooden post was driven into the forest ground to a depth of $10-15 \mathrm{~cm}$. An observation point was set up and marked at the top of the wooden post, which was ensured to be firm. The antennas of a u-blox satellite receiver were placed very close to the observation point. The phase center of the antenna and the observation point were ensured to be on the same plumb line. In addition, a Sanding T-23 receiver was set up at the observation point and started to receive the signal after being strictly centered and leveled (Fig. 3). No less than 200 observation epochs were measured, and the epoch interval was 15 seconds. To obtain the high-accuracy calculation of the 3D coordinates of the forest observation point, the observation lasted for at least 4 hours.

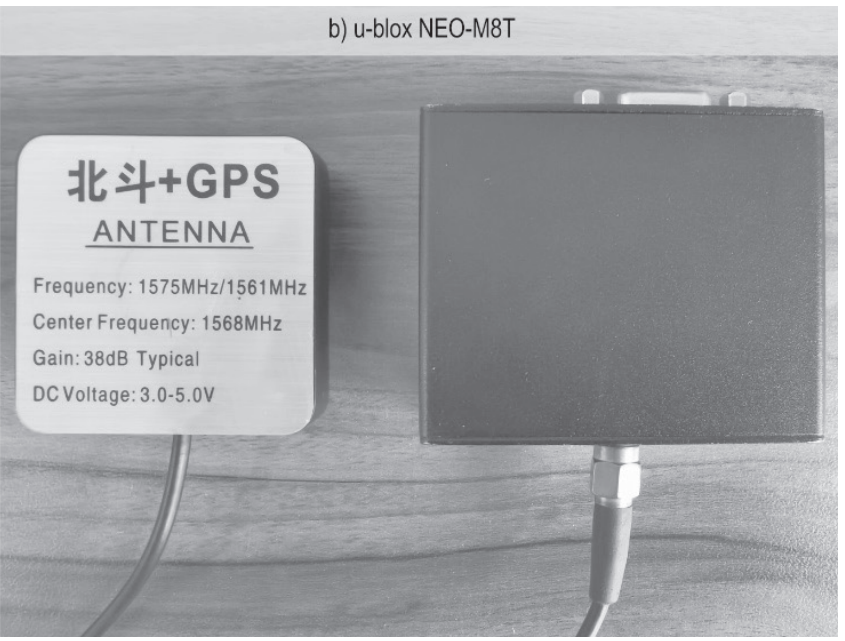

\subsection{Study and Construction of a BDS/GPS- Integrated Algorithm for Forests}

The established BDS/GPS-integrated positioning and observation model for forests in this study is as follows:

$$
\left\{\begin{array}{l}
\rho_{\mathrm{i}}^{\mathrm{B}}=s_{\mathrm{i}}^{\mathrm{B}}-c V_{\mathrm{t}_{\mathrm{R}}}^{\mathrm{B}}+c V_{\mathrm{t}^{\mathrm{s}}}^{\mathrm{B}}-\left(V_{\text {ion }}\right)_{\mathrm{i}}-\left(V_{\text {trop }}\right)_{\mathrm{i}} \\
\rho_{\mathrm{i}}^{\mathrm{G}}=s_{\mathrm{i}}^{\mathrm{G}}-c V_{\mathrm{t}_{\mathrm{R}}}^{\mathrm{G}}+c V_{\mathrm{t}^{\mathrm{s}}}^{\mathrm{G}}-\left(V_{\text {ion }}\right)_{\mathrm{i}}-\left(V_{\text {trop }}\right)_{\mathrm{i}}
\end{array}\right.
$$

Where:

$\rho_{\mathrm{i}} \quad$ observed pseudo range between satellite and receiver

$B, G \quad$ BDS and GPS, respectively

$i \quad$ satellite number

$s_{\mathrm{i}} \quad$ geometric distance between satellite and receiver phase center

c speed of light

$V_{t_{R}} \quad$ receiver clock error, consisting of the clock error of the receiver of each BDS and GPS

$V_{\mathrm{t}} \mathrm{s} \quad$ satellite clock error

$V_{\text {ion }}$ ionospheric delay error

$V_{\text {trop }} \quad$ tropospheric delay error

and the satellite ephemeris error, multipath error and measurement noise are omitted in the equation ( $\mathrm{Li}$ et al. 2016, Gao et al. 2014). The geometric distance between the satellite and the receiver is as follows:

$$
s_{\mathrm{i}}=\sqrt{\left(X_{\mathrm{i}}-x\right)^{2}}+\sqrt{\left(Y_{\mathrm{i}}-y\right)^{2}}+\sqrt{\left(Z_{\mathrm{i}}-z\right)^{2}}
$$

Where:

$X_{\mathrm{i}}, Y_{\mathrm{i}}, Z_{\mathrm{i}}$, coordinates of satellite $i$

$x, y, z \quad$ coordinates of observation point 
A linearized observation equation is obtained by Taylor series expansion at the approximate coordinates $\left(X_{0}, Y_{0}, Z_{0}\right)$ of the observation point. By reorganizing this equation, an indirect adjustment error equation is obtained as follows:

$$
\begin{aligned}
& V_{\mathrm{i}}=l_{\mathrm{i}} V_{\mathrm{X}}+m_{\mathrm{i}} V_{\mathrm{Y}}+n_{\mathrm{i}} V_{\mathrm{Z}}-c V_{\mathrm{tR}}+L_{\mathrm{i}} \\
& \left\{\begin{array}{l}
l_{\mathrm{i}}=\frac{X_{\mathrm{i}}-X_{0}}{\rho_{\mathrm{i}}^{0}} \\
m_{\mathrm{i}}=\frac{Y_{\mathrm{i}}-Y_{0}}{\rho_{\mathrm{i}}^{0}} \\
n_{\mathrm{i}}=\frac{Z_{\mathrm{i}}-Z_{0}}{\rho_{\mathrm{i}}^{0}}
\end{array}\right. \\
& L_{\mathrm{i}}=\rho_{\mathrm{i}}^{0}-s_{\mathrm{i}}+c\left(V_{\mathrm{t} \mathrm{S}}\right)_{\mathrm{i}}-\left(V_{\text {ion }}\right)_{\mathrm{i}}-\left(V_{\text {trop }}\right)_{\mathrm{i}}
\end{aligned}
$$

Where:

$V_{\mathrm{i}} \quad$ observed residual

$V_{\mathrm{X}}, V_{\mathrm{Y}}, V_{\mathrm{Z}}$ observation point coordinate correction values

$L_{\mathrm{i}} \quad$ constant term

$\rho_{\mathrm{i}}^{0} \quad$ distance between the approximate location of the forest observation point and satellite i (Li et al. 2016, Qu et al. 2015)

The BDS/GPS-integrated forest positioning error equation contains 5 unknown parameters. According to the method of least squares, it is necessary to observe no fewer than 5 satellites simultaneously to calculate the location. Assuming that the satellite receiver receives signals from $m$ number of GPS satellites and n number of BDS satellites at a certain observation time $t$, according to equation (3), the integrated positioning error equation can be expressed as follows:

$$
V=B x-L
$$

Where:

$V=\left[\begin{array}{c}V_{1} \\ \vdots \\ V_{\mathrm{m}} \\ V_{\mathrm{m}+1} \\ \vdots \\ V_{\mathrm{m}+\mathrm{n}}\end{array}\right] B=\left[\begin{array}{ccccc}l_{1} & m_{1} & n_{1} & 1 & 0 \\ \vdots & \vdots & \vdots & \vdots & \vdots \\ l_{\mathrm{m}} & m_{\mathrm{m}} & n_{\mathrm{m}} & 1 & 0 \\ l_{\mathrm{m}+1} & m_{\mathrm{m}+1} & n_{\mathrm{m}+1} & 0 & 1 \\ \vdots & \vdots & \vdots & \vdots & \vdots \\ l_{\mathrm{m}+\mathrm{n}} & m_{\mathrm{m}+\mathrm{n}} & n_{\mathrm{m}+\mathrm{n}} & 0 & 1\end{array}\right] x=\left[\begin{array}{c}V_{\mathrm{X}} \\ V_{\mathrm{Y}} \\ V_{\mathrm{Z}} \\ c V_{\mathrm{t}_{\mathrm{R}}}^{\mathrm{B}} \\ c V_{\mathrm{t}_{\mathrm{R}}}^{\mathrm{G}}\end{array}\right] L=\left[\begin{array}{c}L_{1} \\ \vdots \\ L_{\mathrm{m}} \\ L_{\mathrm{m}+1} \\ \vdots \\ L_{\mathrm{m}+\mathrm{n}}\end{array}\right]$

$V$ observed residual

$B$ coefficient matrix

$x$ corrected coordinates and receiver clock error

$L$ constant matrix

The corrected 3D coordinates of the observation point can be calculated using the classic method of least squares as follows:

$$
x=\left(B^{\mathrm{T}} P A\right)^{-1} B^{\mathrm{T}} P L
$$

Where:

$P \quad$ weight of BDS and GPS satellite-observed values Finally, the coordinates of the forest observation point in the WGS-84 coordinate system are obtained as follows:

$$
\left[\begin{array}{c}
X \\
Y \\
Z
\end{array}\right]=\left[\begin{array}{c}
X_{0}+V_{\mathrm{X}} \\
Y_{0}+V_{\mathrm{Y}} \\
Z_{0}+V_{\mathrm{Z}}
\end{array}\right]
$$

\subsubsection{Temporal and Spatial Unification}

The time-space references used in satellite navigation consist of a time reference and a coordinate reference. The GPS uses the GPS time (GPST) and the WGS84 coordinate system, whereas the BDS uses the BeiDou time (BDT) and the China Geodetic Coordinate System 2000 (CGCS-2000) coordinate system. If these two systems are integrated for positioning, their time-space references must be unified.

With respect to the spatial coordinate reference, the WGS-84 and the CGCS-2000 coordinate systems are the same in the definitions of the origin of the coordinates, the scale, the coordinate axes and changes in the directions of the coordinate axes with time. They only differ slightly in oblateness, whose effect is on the submillimeter level. Therefore, the difference in oblateness between the two systems is negligible. According to the accuracy requirement of forest surveys, the spatial coordinate references for the two systems can be viewed as equivalent (Paziewski et al. 2017).

With respect to the time reference, the BDT and GPST are both atomic time and count in seconds and numbers of weeks. However, there is a difference in the start of the time counting between the BDT and GSPT. There is a starting time difference of 1356 weeks between the BDT and GPST. The conversion equation for the BDT and GPST is thus as follows (Yang et al. 2016):

$$
t_{\mathrm{GPS}}=t_{\mathrm{BDS}}+1356 \times 604800+14
$$

Where:

$\begin{array}{ll}t_{\mathrm{GPS}} & \text { GPS time } \\ t_{\mathrm{BDS}} & \text { BeiDou time }\end{array}$

\subsubsection{Observation Weight Determination}

When positioning in a forest, the elevation angle between the observation point and each satellite has a relatively significant impact on the positioning accuracy of the observed value. Elevation angle weight determination refers to the determination of the weight of the observed value based on the elevation 
angle of each satellite used in observation. Different elevation angles lead to different ranging code transmission paths, which in turn lead to different errors. When positioning in a forest, if the elevation angle of a satellite is too small, its signals can be very easily blocked by the tree canopy. Correspondingly, the number of signal transmission paths in the forest increases and the ionospheric delay, tropospheric delay and multipath effects on the ranging codes transmitted by the satellite may increase, resulting in an increase in the measurement error in the distance between the station and the satellite. Therefore, the use of a reasonable elevation angle weight can help to obtain more accurate positioning results (Yang et al. 2016). The following elevation angle weight determination model is used in this study:

$$
P=E / 90^{\circ}
$$

Where:

E elevation angle corresponding to the observed value Observation weight determination was the key of this research and was well integrated and written in RTKLIB software.

\subsection{Accuracy Evaluation}

\subsubsection{Analysis of the Characteristic Factors for Positioning Accuracy}

The number of visible satellites (NVS), the PDOP value and SNR are important metrics that characterize satellite positioning accuracy. Under normal circumstances, a larger number of visible satellites forms a better geometric pattern formed by the satellites and the observation station, resulting in a lower PDOP value and a higher $\mathrm{SNR}$, i.e., more accurate final positioning results. Therefore, when comparing BDS/GPS-integrated and GPS positioning in forests, it is necessary to first compare the aforementioned three factors. In this study, the RTKLIB software was used to extract the NVS, PDOP value, SNR data and patterns in the data.

\subsubsection{Accuracy Analysis of Positioning Results}

The experimental results are comparatively analyzed from the perspectives of theoretical and actual accuracies.

\subsubsection{Theoretical Accuracy}

Based on equations (6)-(8), the error expression and the equation for calculating accuracy are obtained as follows:

$$
\begin{gathered}
D=\sigma_{0}^{2} Q \\
\sigma_{0}= \pm \sqrt{\frac{V^{\mathrm{T}} P V}{n-t}}
\end{gathered}
$$

$$
Q=\left(B^{\mathrm{T}} P B\right)^{-1}
$$

Where:

$Q$ inverse matrix of the unknown coefficient matrix of the normal equation, which is also referred to as the cofactor matrix or the accuracy matrix

$D$ medium error of the corresponding unknown parameters $(X, Y, Z$ and receiver clock error), i.e., theoretical accuracy

unit weight MSE

$n$ number of observed values

$t=5$

$V$ residual error of observed values

\subsubsection{Actual Accuracy}

The actual conditions involved in positioning in the field are complex; therefore, positioning results are often affected by a combination of accidental and residual system errors. This means that there may be a certain difference between the actual and theoretical accuracies. Therefore, it is necessary to estimate the actual accuracy of the positioning results obtained using the BDS/GPS-integrated algorithm. By comparing the 3D coordinates of the observation point obtained using the BDS/GPS-integrated algorithm and the GPS algorithm, with the true coordinates of the observation point obtained from a high-accuracy calculation of the carrier phase using the GAMIT software (observed value - true value), changes in error for each epoch can be obtained. In addition, the actual positioning accuracy is evaluated using equation (12) as follows (Balenović et al. 2018, Xu et al. 2020):

$$
\left\{\begin{array}{l}
\Delta x=\sqrt{\frac{\sum_{\mathrm{i}=1}^{\mathrm{n}}\left(X_{\mathrm{i}}-\tilde{X}\right)^{2}}{n}} \\
\Delta y=\sqrt{\frac{\sum_{\mathrm{i}=1}^{\mathrm{n}}\left(Y_{\mathrm{i}}-\tilde{Y}\right)^{2}}{n}} \\
\Delta z=\sqrt{\frac{\sum_{\mathrm{i}=1}^{\mathrm{n}}\left(Z_{\mathrm{i}}-\tilde{Z}\right)^{2}}{n}}
\end{array}\right.
$$

Where:

$$
\begin{array}{ll}
\Delta x, \Delta y, \Delta Z \text { actual positioning accuracies in } X, Y \text { and } Z \\
\text { directions, respectively } \\
n
\end{array} \begin{aligned}
& \text { number of observed values } \\
& \text { true coordinates of the receiver in } X, Y \text { and } \\
& Z \text { directions, respectively } \\
& X_{\mathrm{i},}, Y_{\mathrm{i}}, Z_{\mathrm{i}} \quad \begin{array}{l}
\text { coordinates calculated using BDS/GPS-in- } \\
\text { tegrated positioning algorithm or GPS po- } \\
\text { sitioning algorithm }
\end{array}
\end{aligned}
$$




\section{Results and Discussion}

\subsection{NVS}

The number of visible satellites (NVS) that could be observed during the whole period of positioning under the forest canopy and the corresponding signal quality were recorded using the RTKLIB software. In the broad-leaved forest area, for the BDS/GPS-integrated positioning algorithm, there was a total of 15-23 satellites available for positioning and observation
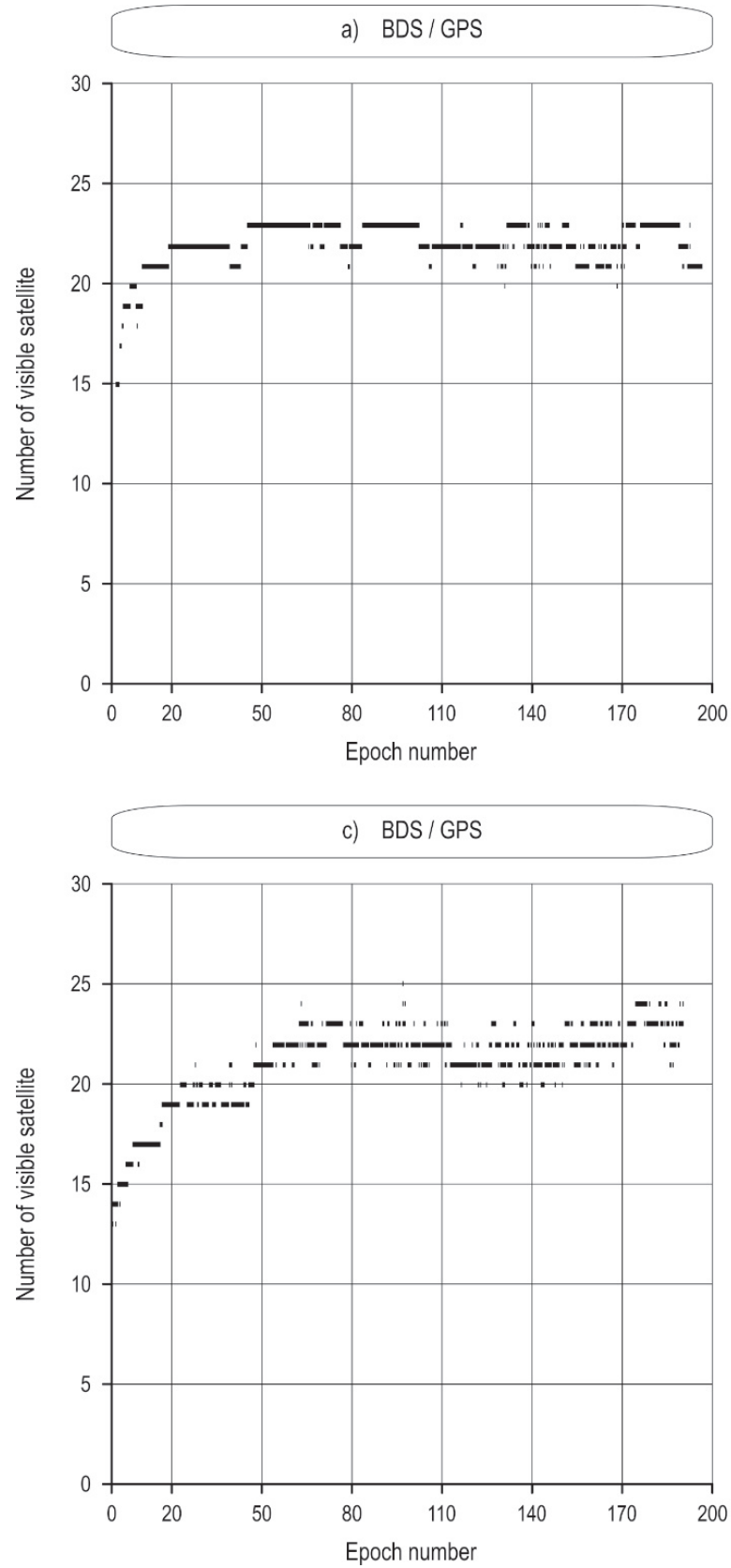

during the observation period, including 11 GPS satellites and 12 BDS satellites (Figs. $4 \mathrm{a}$ and b). In the Coniferous forest, there was a total of 13-27 satellites available for positioning and observation including 11 GPS satellites and 16 BDS satellites (Figs. $4 \mathrm{c}$ and d).

Figs. $5 \mathrm{a}-\mathrm{d}$ show the continuity of the received signals, $a-b$ was the signals received situation in broadleaved forest, while $\mathrm{c}-\mathrm{d}$ was the signals received situation in Coniferous forest. A continuous reception of signals (e.g. those from the G04, G14, C09 in Fig. 5 a-b
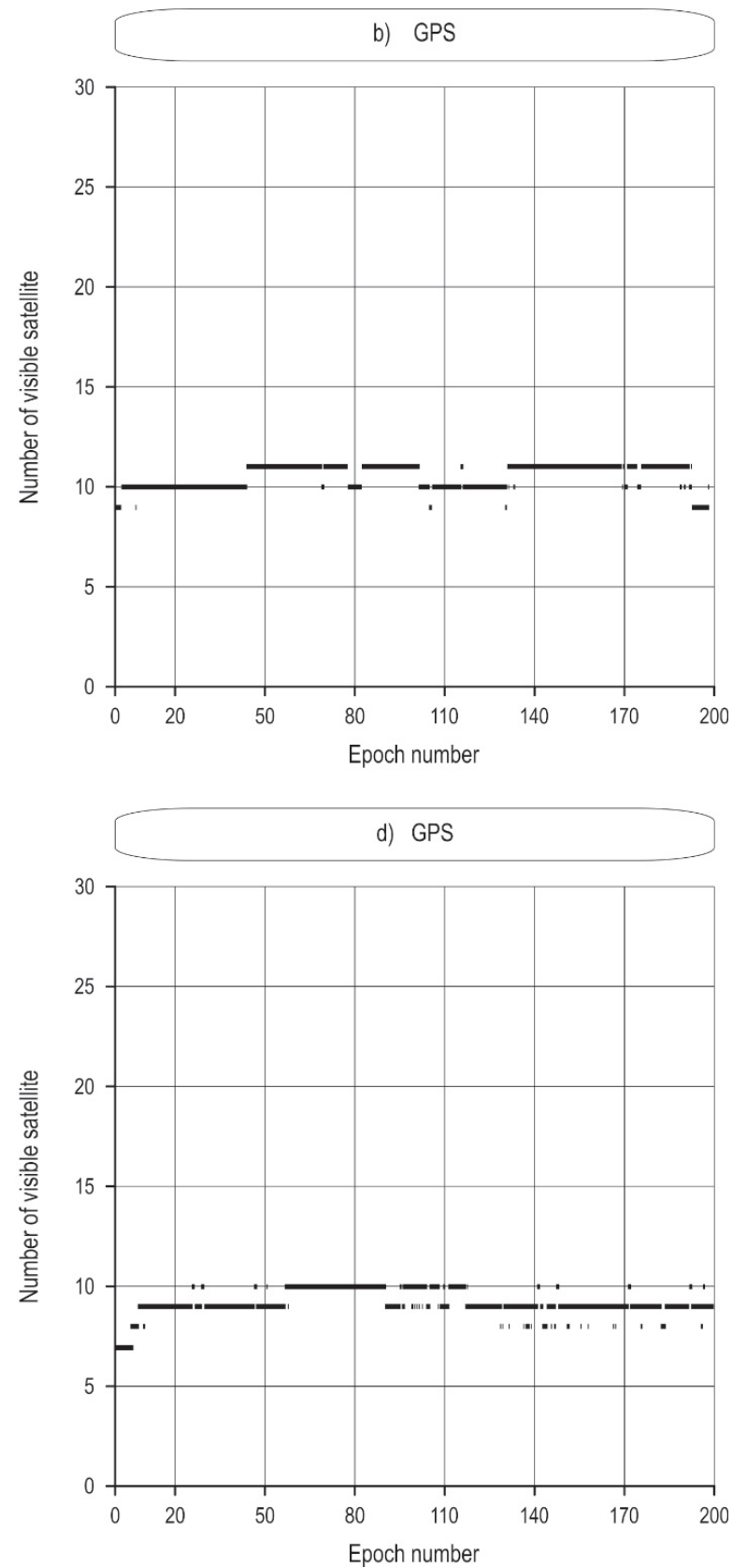

Fig. 4 Satellite visible number comparison 

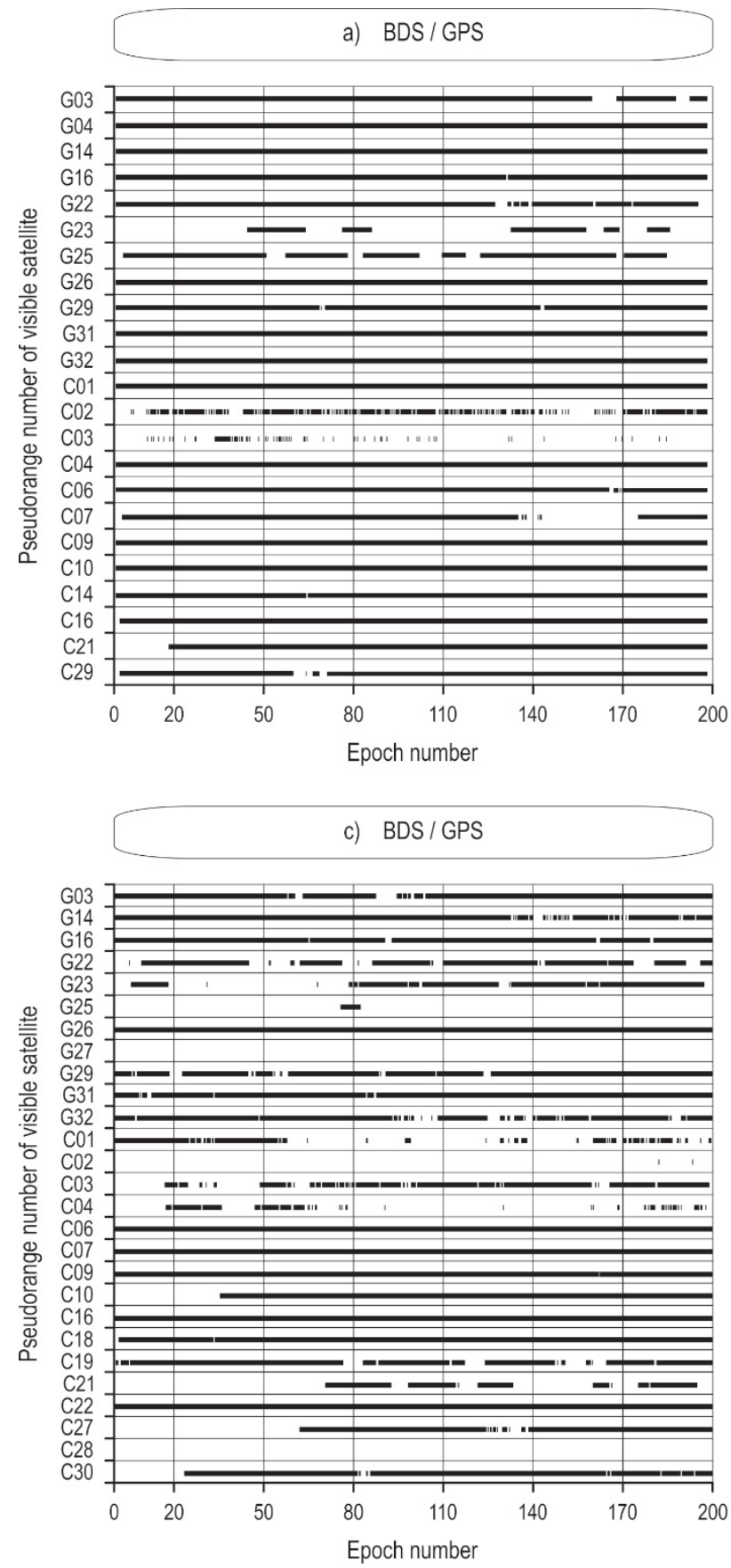

Fig. 5 Signal continuity comparison

and G26, C06, C09 satellites, as shown in Fig. 5 c-d indicates relatively high signal quality. The reception of signals from the G23, C03 satellites in a-b and the G23, C01, C21 satellites shown in c-d were intermittent, suggesting that losses of the satellite lock might have occurred during the observation period. In addition, there were more than four visible satellites for the
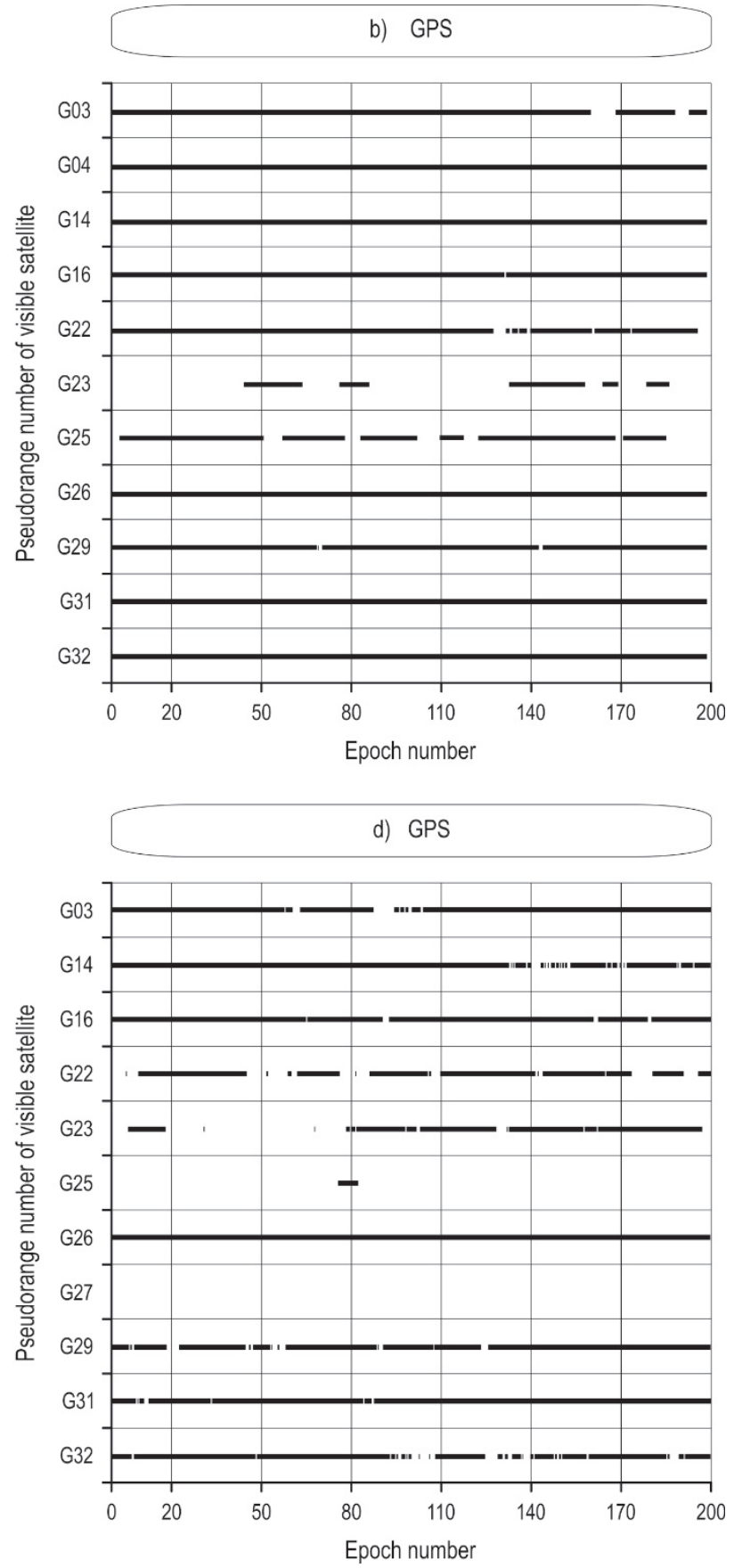

BDS/GPS-integrated positioning and the GPS positioning, meeting the requirement of the necessary number of observed values for the calculation of coordinates. However, there were more visible satellites for the BDS/GPS-integrated positioning than for the GPS positioning, suggesting that the integrated positioning algorithm can have an excess number of 
observed values for the calculation when used for positioning in forests and, consequently, produce more accurate positioning results.

\subsection{PDOP Value}

The PDOP value refers to the 3D PDOP factor, which is an important metric that reflects the strength of the geometric pattern formed by the observation point and the satellites at the observation time. It is also used to evaluate the positioning capacity of a satellite navigation system (Cai et al. 2011, Li et al. 2014). As demonstrated in Figs. 6 a-d, the PDOP values for BDS/ GPS-integrated positioning and observation ranged from 0.7 to 1.8 in broad-leaved forest as shown in Fig. $6 \mathrm{a}-\mathrm{b}$, while the PDOP value changed steadily ranging from 1.1 to 1.9 in coniferous forest, whereas the PDOP values for GPS positioning ranged from 1.0 to 2.1 in broad-leaved forest and from 1.6 to 2.5 in coniferous forest. The PDOP values for BDS/GPS-integrated positioning were lower than those for GPS positioning, suggesting that the use of BDS/GPS-integrated positioning in forests of different vegetation types significantly increased the strength of the geometric pattern formed by the observation station and the satellites and thereby improved the accuracy of the positioning results.
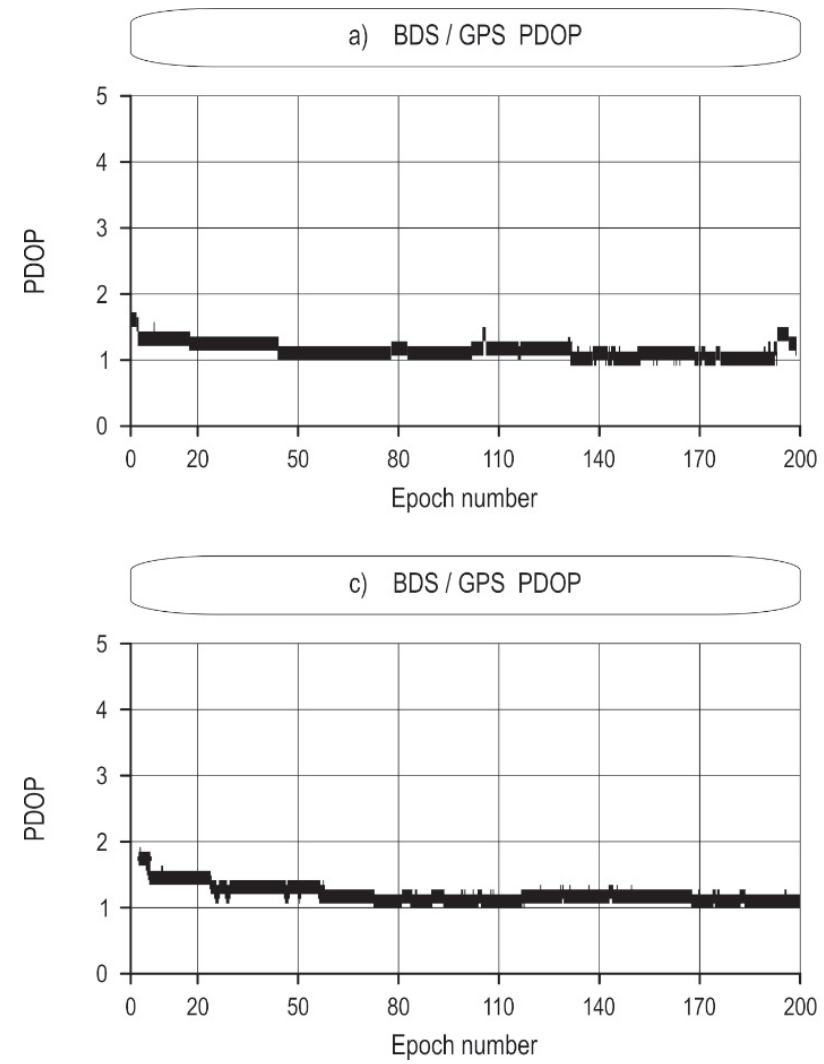

\subsection{SNR}

SNR refers to the ratio of the strength of a signal received by a receiver to the strength of the noise. Generally speaking, a higher SNR implies less noise in the signal, a higher satellite signal quality, and more accurate positioning results (Khodabandeh et al. 2016, Gao et al. 2015). As demonstrated in Figs. 7 a-d, in the two forest experimental areas of two different types, the SNRs of the satellite signals received during the observation period were in the range of $10-50 \mathrm{~dB}$ and mostly in the range of 30-45 $\mathrm{dB}$, suggesting relatively strong satellite signals. In addition, as the BDS/GPSintegrated positioning algorithm significantly increased NVS for positioning under the forest canopy, the SNRs of the signals from the BDS/GPS satellites were more stable than those from the GPS satellites alone and the accuracy of the BDS/GPS-integrated positioning algorithm was higher than that of the GPS positioning algorithm.

\subsection{Theoretical Accuracy}

Two hundred continuous epochs with stable signals were selected for the accuracy calculation. The theoretical accuracies of the BDS/GPS-integrated
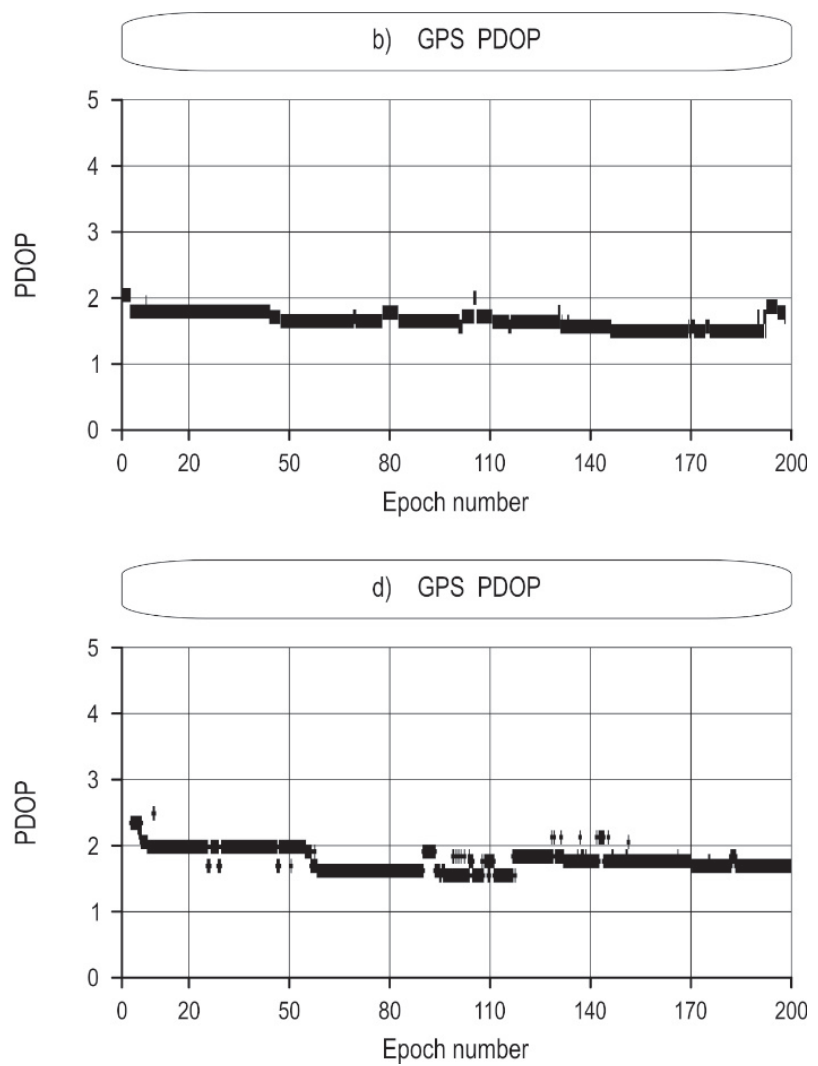

Fig. 6 PDOP comparison 

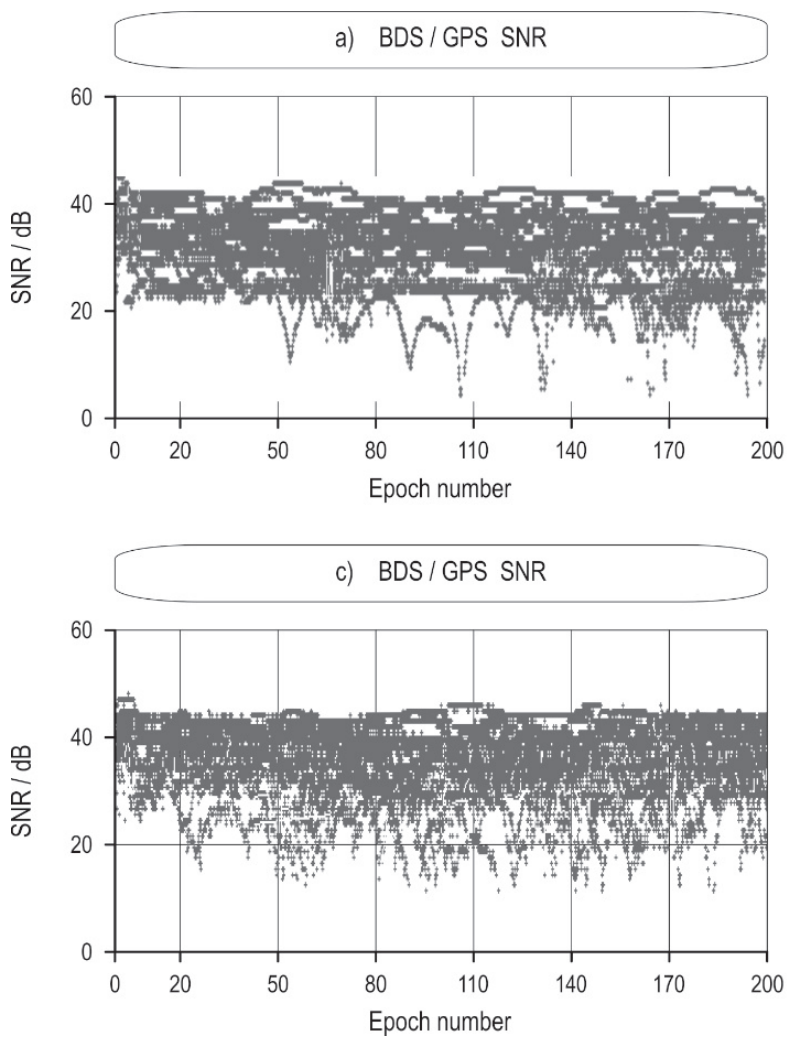

Fig. 7 SNR comparison

positioning algorithm for forests and the GPS positioning algorithm were obtained. Table 2 summarizes the theoretical accuracies of the results obtained using the two positioning algorithms, based on equation (11).

The theoretical accuracy analysis shows that, no matter in which vegetation types, there was no significant difference between the results obtained using the BDS/GPS-integrated positioning and GPS positioning algorithms in the $X$ direction, but the theoretical accuracy of the results obtained using the BDS/ GPS-integrated positioning algorithm were smaller than those of the results obtained using the GPS positioning algorithm in the $Y$ and the $Z$ directions. These results are in agreement with the network characteristics of the BDS.

Table 2 Theoretical accuracy of positioning results

\begin{tabular}{|l|c|c|c|}
\hline \multicolumn{1}{|c|}{ Positioning algorithm } & $X / \mathrm{m}$ & $\mathrm{Y} / \mathrm{m}$ & $Z / \mathrm{m}$ \\
\hline BDS/GPS, broad-leaved forest & 2.311 & 3.312 & 3.023 \\
\hline GPS, broad-leaved forest & 2.395 & 4.865 & 4.734 \\
\hline BDS/GPS, coniferous forest & 1.830 & 3.102 & 2.857 \\
\hline GPS, coniferous forest & 2.096 & 4.152 & 4.460 \\
\hline
\end{tabular}
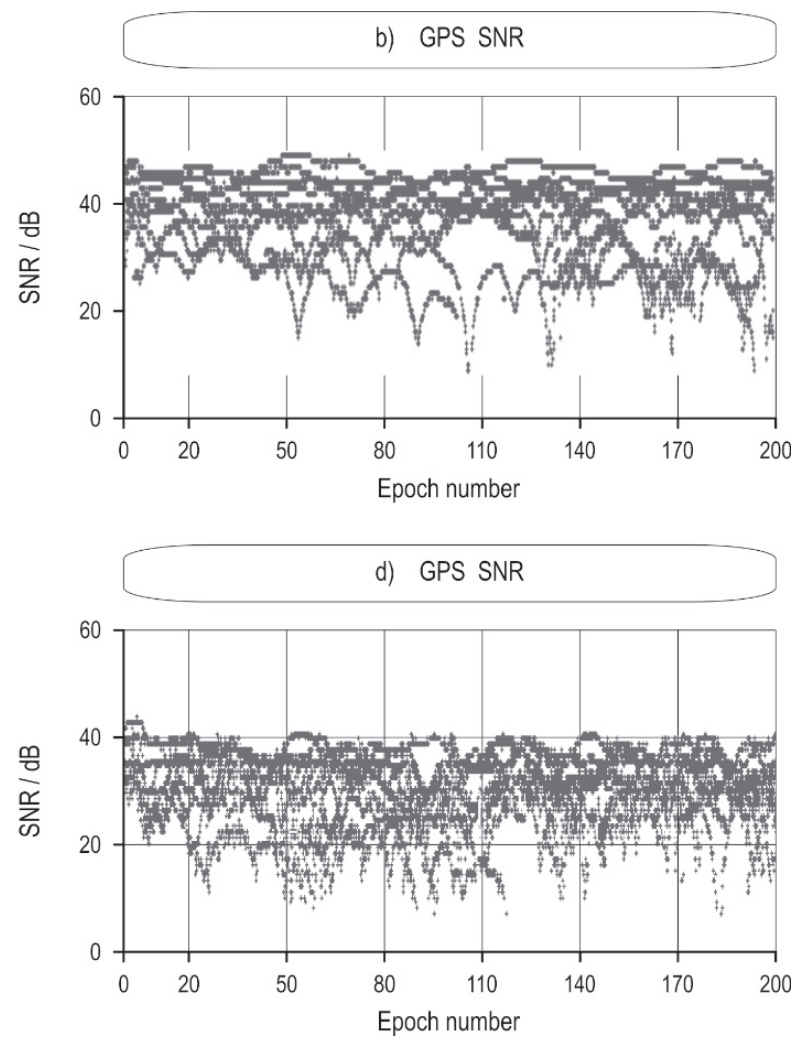

\subsection{Actual Accuracy}

The absolute error of the results for each epoch in the $X, Y$ and $Z$ directions were determined by comparing the calculated data used in Section 4.4 with the true coordinates of the observation point obtained by Sanding T-23 receiver and GAMIT software, as shown in Figs. 8 to 11 .

The data show that, in the broad-leaved forest, the error of the results obtained using the BDS/GPS-integrated positioning algorithm for forests fluctuated around $0 \mathrm{~m}$ and its extreme value did not exceed $8 \mathrm{~m}$. Its absolute value in the $Z$ direction exceeded $20 \mathrm{~m}$. In the coniferous forest, the error of the results obtained using the BDS/GPS-integrated positioning algorithm also fluctuated around $0 \mathrm{~m}$ and its extreme value in $X$ direction did not exceed $4 \mathrm{~m}$, in $Y$ and $Z$ directions, the extreme value was lower than $10 \mathrm{~m}$. It showed that, in forests of different vegetation types, the error of the results obtained using the GPS positioning algorithm alone was significantly greater than that of the results obtained using the BDS/GPS-integrated positioning algorithm.

The actual accuracies of the two algorithms for positioning under the forest canopy were analyzed using 

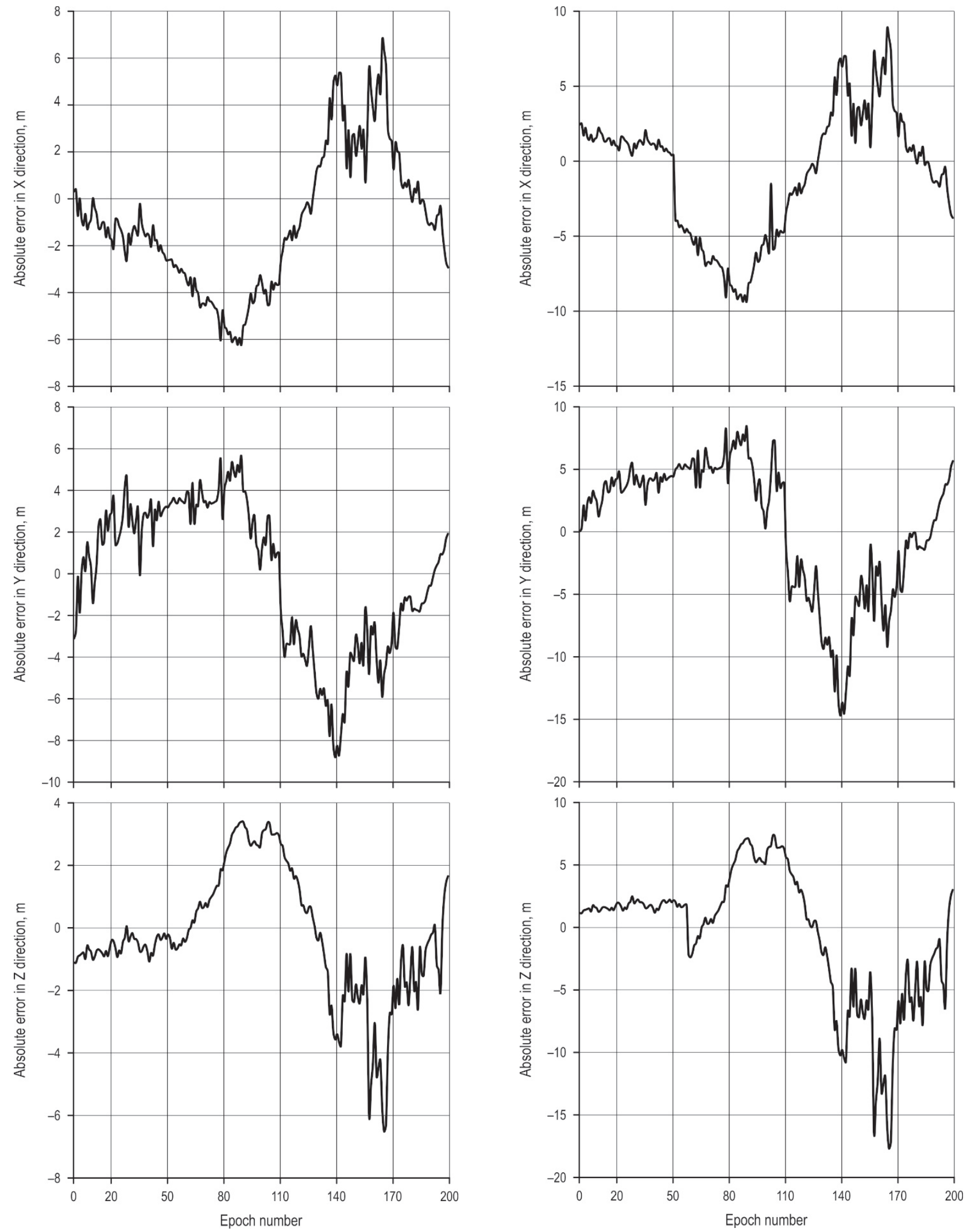

Fig. 8 Absolute error of BDS/GPS-integrated positioning in $X, Y$ and $Z$ directions in broad-leaved forest

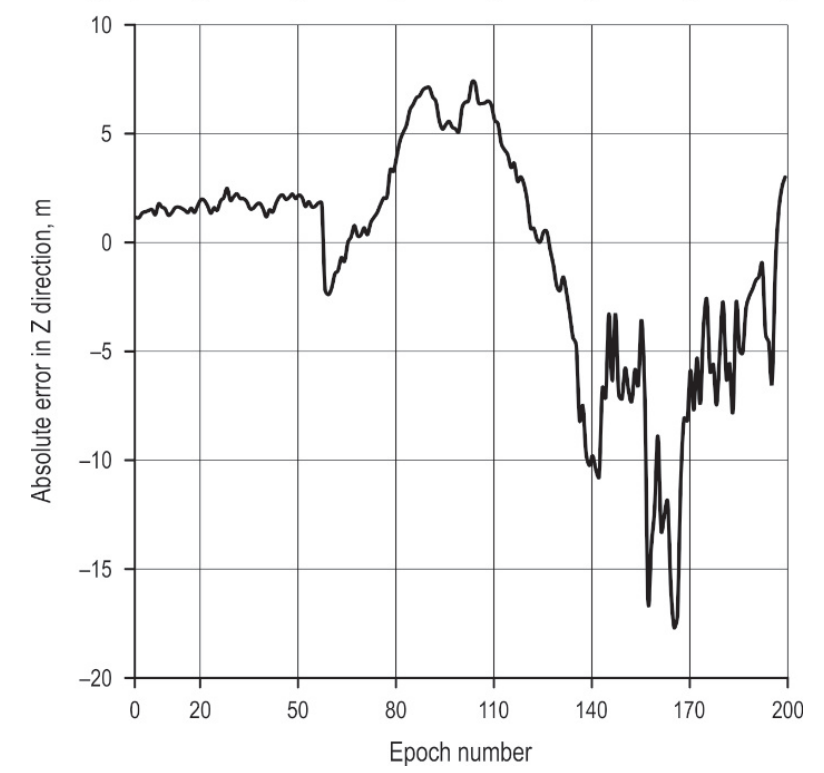

Fig. 9 Absolute error of GPS positioning in $X, Y$ and $Z$ directions in broad-leaved forest 

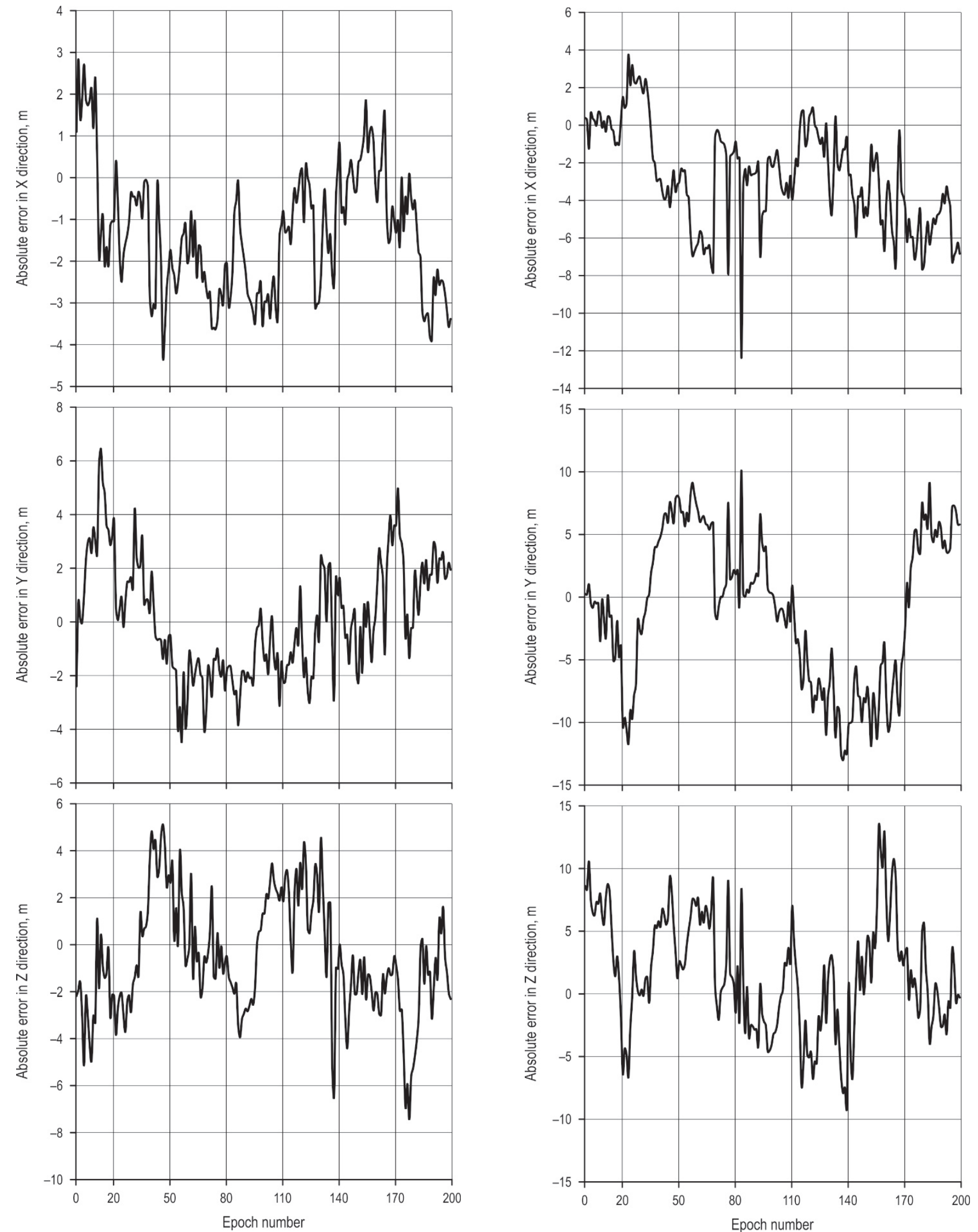

Fig. 10 Absolute error of BDS/GPS-integrated positioning in $X, Y$ and $Z$ directions in coniferous forest

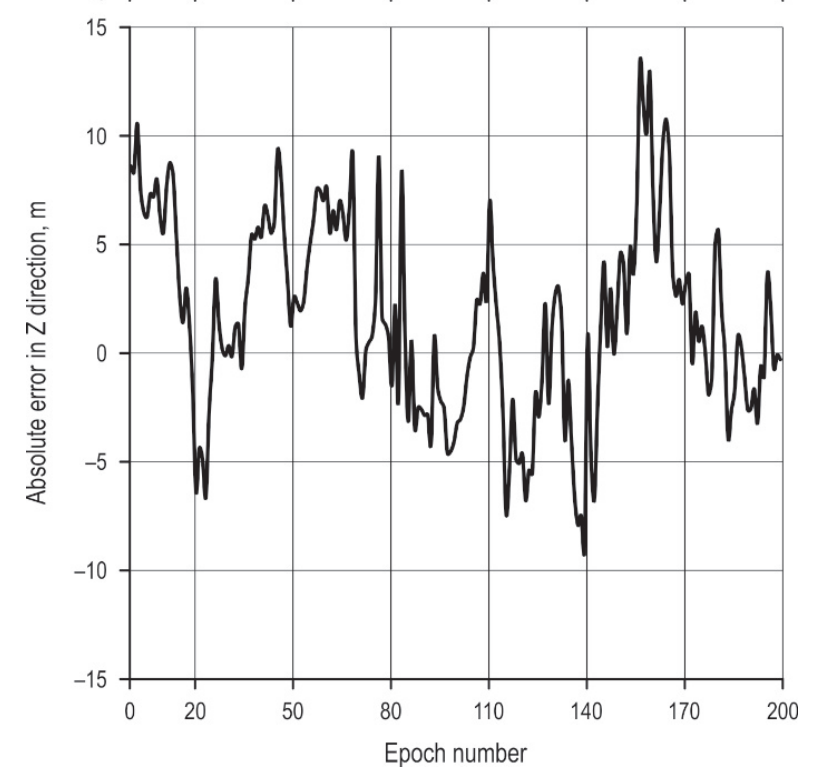

Fig. 11 Absolute error of GPS positioning in $X, Y$ and $Z$ directions in coniferous forest 
Table 3 Actual accuracy of positioning results

\begin{tabular}{|l|c|c|c|}
\hline \multicolumn{1}{|c|}{ Positioning algorithm } & $X / \mathrm{m}$ & $\mathrm{Y} / \mathrm{m}$ & $\mathrm{Z} / \mathrm{m}$ \\
\hline BDS/GPS, broad-leaved forest & 3.172 & 3.551 & 4.126 \\
\hline GPS, broad-leaved forest & 4.976 & 5.363 & 7.261 \\
\hline BDS/GPS, coniferous forest & 2.004 & 2.140 & 2.564 \\
\hline GPS, coniferous forest & 3.842 & 5.286 & 5.410 \\
\hline
\end{tabular}

equation (12). Table 3 summarizes the actual accuracies in the $X, Y$ and $Z$ directions.

A comparison of the actual accuracies of the four sets of data shows that the error in positioning in the high-canopy density forest stand using the GPS algorithm alone was relatively large; the largest error in the $Z$ direction was $7.261 \mathrm{~m}$. The comparison showed that the results obtained using the BDS/GPS-integrated positioning algorithm were closer to the true values. The components of the error of the results obtained using the BDS/GPS-integrated positioning algorithm in the $X$ directions were relatively close to one another, whereas the component of the error in the $Y$ and $Z$ direction was relatively large. The components of the error of the results obtained using the BDS/GPS-integrated positioning algorithm in the three directions were significantly smaller than those obtained using the GPS positioning algorithm.

\section{Conclusion}

Using the forestlands of typical vegetation types in Jiufeng National Forest Park and Dongsheng Bajia forest farm in the Haidian District of Beijing, China as the study area, a BDS/GPS-integrated positioning algorithm was developed by creating interoperability between the BDS and the GPS and setting the system weights. The algorithm was also written into the RTKLIB software to obtain positioning results by direct calculation, while receiving signals from the two satellite systems. The results obtained from this study show the following. Under the obstructing conditions in the high-canopy dense forest, the NVS of the BDS/GPSintegrated system was significantly higher than that of the GPS alone. The PDOP values for integrated positioning were better than those for GPS positioning. The SNRs of the signals from the BDS/GPS-integrated positioning satellites were higher and more stable than those from the GPS positioning satellites. The comparison of the theoretical and actual accuracies of the results of positioning under the forest canopy shows that the accuracy of the BDS/GPS-integrat- ed single-point positioning algorithm was notably superior to that of the GPS positioning algorithm. Additionally, it can be inferred that since the BDS/GPSintegrated positioning algorithm can significantly increase NVS and the high-orbit (GEO and IGSO) satellites of the BDS can reduce the multipath error, the geometric patterns of the satellites is strengthened when compared to the GPS. Therefore, the accuracy advantage of the BDS/GPS-integrated positioning algorithm should become more pronounced in regions with higher forest canopy densities or more complex terrains.

This study investigated two high-canopy density forest regions in Beijing. Further experimental verification is required for other complex environments, such as forestlands and canyons with various vegetation types, terrain and topographical conditions. As the BDS is continuously being improved, it can be expected that multi-system-integrated positioning approaches could provide more stable and accurate positioning, time and navigation services for monitoring and management of forest resources in forest environments with higher canopy densities and more complex terrains.

\section{Acknowledgements}

Financial support for this study was supported by National Natural Science Foundation of China (Project No. 31800468). We are grateful to the undergraduate students and staff of the Laboratory of Forest Management and »3S « technology and Beijing Forestry University.

\section{References}

Balenović, I., Gašparović, M., Milas, A.S., Berta, A., Seletković, A., 2018: Accuracy assessment of digital terrain models of lowland pedunculate oak forests derived from airborne laser scanning and photogrammetry. Croatian Journal of Forest Engineering 39(1): 117-128.

Becker, R.M., Keefe, R.F., Anderson, N.M., 2017: Use of realtime GNSS-RF data to characterize the swing movements of forestry equipment. Forests 8(2): 44. https://doi.org/10.3390/ f8020044

Bettinger, P., Merry, K., Bayat, M., Tomaštík, J., 2019: GNSS use in forestry - A multi-national survey from Iran, Slovakia and southern USA. Computers and Electronics in Agriculture 158: 369-383. https://doi.org/10.1016/j.compag.2019.02.015

Brach, M., Zasada, M., 2014: The effect of mounting height on GNSS receiver positioning accuracy in forest conditions. Croatian Journal of Forest Engineering 35(2): 245-253. 
Chen, G.Y., 2004: Application of global positioning in forestry. Journal of Beijing Agricultural College 19(3): 46-48.

Cai, C.S., Dai, W.J., Kuang, C.L., 2011: Calculation and analysis of PDOP for combined GPS/GLONASS systems. Bulletin of Surveying and Mapping (11): 5-7.

Feng, Z.K., Yan, F., Mohammad, R.U., Dang, Y., 2017: Developing a volume model using south NTS-372R total station without tree felling in a Populus canadensis moench plantation in Beijing, China. Croatian Journal of Forest Engineering 38(1): 127-150.

Gao, W., Gao, C.F., Pan, S., Wang, D., Wang, S., 2015: Singleepoch positioning method in network RTK with BDS triplefrequency. Acta Geodaetica et Cartographica Sinica 44(6): 641-648. https://doi.org/10.11947/j.AGCS.2015.20140308

Isao, S., Yuko, S., Shiro, T., 2005: A study of the effects of stems and canopies on the signal to noise ratio of GPS signals. Journal of Forest Research 10(5): 395-401. https://doi. org/10.1007/s10310-005-0158-7

Jia, H.X., Xing, H.Y., Jia, H.S., 2009: Application of GPS technology in forestry. Inner Mongolia Forestry Investigation and Design 32(3): 78-80®

Jiang, Z.X., Zhang, H., Guo, Z.H., 2010: The method for calculation of internal accord accuracy in airborne gravity survey. Geophysical \& Geochemical Exploration 34(5): 672-676.

Kaartinen, H., Hyyppä, J., Vastaranta, M., Kukko, A., Jaakkola, A., Yu, X., Pyörälä, J., Liang, X., Liu, J., Wang, Y., Kaijaluoto, R., Melkas, T., Holopainen, M., Hyyppä, H., 2015: Accuracy of kinematic positioning using global satellite navigation systems under forest canopies. Forests 6(9): 32183236. https://doi.org/10.3390/f6093218

Khodabandeh, A., Teunissen, P., 2016: PPP-RTK and intersystem biases: the ISB look-up table as a means to support multi- system PPP-RTK. Journal of Geodesy 90(9): 837-851. https://doi.org/10.1007/s00190-016-0914-9

Lai, J.M., 2005: Application research of GPS technology in positioning and area measurement in forest resources survey in low mountain areas of western Sichuan. Chengdu, Sichuan Agricultural University.

Li, B., Li, Z.H., Liu, W.K., 2013: Simulation analysis of combined system of COMPASS/ GPS / GLONASS in china region. Journal of Geodesy and Geodynamics 33(6): 94-97.

Li, P., Zhang, X., 2014: Modeling and performance analysis of GPS/GLONASS/BDS precise point positioning. China Satellite Navigation Conference (CSNC) 2014 Proceedings, Volume III. Springer Berlin Heidelberg, 251-263.

Li, Y.N., Liu, L.M., Cui, L., Huang, L., Zhao, Z., Huang, X., 2014: Effects of canopy openness on positioning availability and initialization time of GNSS RTK in forests. Scientia Silvae Sinicae 50(2): 78-84. https://doi.org/10.11707/j.10017488.2014021

Li, Z.H., Huang, J.S., 2016: GPS Measurement and Data Processing. Wuhan, Wuhan University Press.
Liu, J., Hyyppä, J., Yu, X., Jaakkola, A., Kukko, A., Kaartinen, H., Zhu, L., Liang, X., Wang, Y., Hyyppä, H., 2017: A novel GNSS technique for predicting boreal forest attributes at low cost. IEEE Transactions on Geoscience and Remote Sensing 55(9): 4855-4867. https://doi.org/10.1109/TGRS.2017.2650944

Liu, J.Y., 2003: Principle and method of GPS satellite navigation and positioning. Beijing, Science Press, 399-401.

Liu, J.Y., 2011: Some suggestion for enhancing compass navigation performance. Digital Communication World 2: 31-35.

Liu, J.Y., 2013: Status and development of the Beidou navigation satellite system. Journal of Telemetry, Tracking and Command 34(3): 1-8.

Liu, J.Y., 2015: Development thinking on GNSS signal receivers-transmitting/receiving issue (14) of GNSS navigation signals. Digital Communication World 10: 1-9.

Michael, G.W., Aarone, E., 2006: Standard and real-time accuracy and reliability of a mapping-grade GPS in a coniferous western Oregon forest. Western Journal of Applied Forestry 21(4): 222-227. https://doi.org/10.1093/wjaf/21.4.222

Montenbruck, O., Steigenberger, P., Prange, L., Deng, Z., Zhao, Q., Perosanz, F., Romero, I., Noll, C., Stürze, A., Weber, G., Schmid, R., MacLeod, K., Schaer, S., 2017: The multiGNSS experiment (MGEX) of the international GNSS service (IGS) - achievements, prospects and challenges. Advances in space research 59(7): 1671-1697. https://doi.org/10.1016/j. asr.2017.01.011

Yuzao, N., Zhongke, F., Xiangrui, D., Xiaokun, W., 2004: Effects of crown cover and hill country on RTD GPS positioning precision and corresponding reducing countermeasures. Journal of Beijing Forestry University 26(2): 1-5.

Paziewski, J., Sieradzki, R., 2017: Integrated GPS+BDS instantaneous medium baseline RTK positioning: signal analysis, methodology and performance assessment. Advances in Space Research 60(12): 2561-2573. https://doi.org/10.1016/j. asr.2017.04.016

Qu, L., Zhao, Q., Guo, J., Wang, G., Guo, X., Zhang, Q., Jiang, K., Luo, L., 2015: BDS/GNSS real-time kinematic precise point positioning with un-differenced ambiguity resolution. China Satellite Navigation Academic Annual Meeting, 1329.

Solarić, N., Solarić, M., Bogdanovski, Z., Dimeski, S., 2018: Three days before the earthquake in skopje there was a compression of the earth's crust. Geodetski list 72(1): 15-35.

Tan, W., Wang, K.L., Luo, X., Wang, Z.-J., 2008: Positioning precision with handset GPS receiver in different stands. Journal of Beijing Forestry University 30(3): 163-167.

Xu, W., Su, Z., Feng, Z., Xu, H., Jiao, Y., Yan, F., 2013: Comparison of conventional measurement and LiDAR-based measurement for crown structures. Computers and Electronics in Agriculture 98: 242-251. https://doi.org/10.1016/j. compag.2013.08.015 
Xu, W., Huang, S., Wu, C., Xiong, Y., Wang, L., Lu, N., Kou, W., 2020: The pruning phenological phase-based method for extracting tea plantations by field hyperspectral data and Landsat time series imagery. Geocarto International: 1-21. https://doi.org/10.1080/10106049.2020.1801859

Yan, F., Wang, C.B., Wu, Y.R., Lin., L., Feng, Z., 2019: Algorithm Implementation and Precision Analysis of Forest BDS/ GPS Combined Positioning. Transactions of the Chinese Society for Agricultural Machinery 50(4): 221-227. https:// doi.org/10.6041/j.issn.1000-1298.2019.04.025

Yang, Y.X., Lu, M.Q., Han, C.H., 2016: Some notes on interoperability of GNSS. Acta Geodaetica et Cartographica Sinica 45(3): 253-259. https://doi.org/10.11947/j. AGCS.2016.20150653

Zhang, H.C., Zhou, H.P., Zheng, J.Q., 2014: Effects of the site condition and positioning mode on GPS performance for precision forestry. Journal of Nanjing Forestry University (Natural Sciences Edition) 38(6): 72-76.
Zhang, J.Q., Pan, L., Wang, S.G., 2012: Photogrammetry. Wuhan, Wuhan University Press, 90-93.

Zhang, X.Q., Zhang, X., Yu, X.W., Deng, G., Ma, Y., 2015: Study on satellite-ground combining positioning in high canopy stands. Journal of Nanjing Forestry University (Natural Sciences Edition) 39(3): 25-28.

Zhao, Y.D., Tu, J.Y., 2018: Intelligent surveying and mapping system of forest inspection based on Beidou Satellite. Transaction of the Chinese Society for Agricultural Machinery 49(7): 177-185. https://doi.org/10.6041/j.issn.10001298.2018.07.022

Zhu, N., Marais, J., Bétaille, D., Berbineau, M., 2018: GNSS position integrity in urban environments: A review of literature. IEEE Transactions on Intelligent Transportation Systems 19(9): 2762-2778. https://doi.org/10.1109/ tits.2017.2766768

Zrinjski, M., Barković, Đ., Matika, K., 2019: Development and modernization of GNSS. Geodetski list 73(1): 45-65.

(C) 2021 by the authors. Submitted for possible open access publication under the terms and conditions of the Creative Commons Attribution (CC BY) license (http://creativecommons.org/licenses/by/4.0/).

Received: July 21, 2020

Accepted: October 10, 2020
Authors' addresses:

Asocc. prof. Fei Yan, PhD*

e-mail: yf-perfect@163.com

Xueqi $\mathrm{Hu}, \mathrm{MSc}$

e-mail: 969616662@qq.com

Lidan Xu, MSc

e-mail: xlidan@bjfu.edu.cn

Yongrui Wu, BSc

e-mail: 1427663547@qq.com

Precision Forestry Key Laboratory of Beijing

College of Forestry

Beijing Forestry University

100083 Beijing

P.R. CHINA

* Corresponding author 